\title{
Effects of the Rainy Ambiance on Weight Change, Haemodynamic and Thermoregulatory Adaptations in Congolese Football Players
}

\section{Moulongo Jean Georges André ${ }^{1,2}{ }^{*}$, Massamba Alphonse ${ }^{1}$, Pela Lola Christophe ${ }^{3}$, Mantari Jean Didier ${ }^{1}$, Packa Tchissambou Bernard1}

${ }^{1}$ Laboratory for Exercise Physiology and Biomechanics, Higher Institute of Physical Education and Sports (ISEPS), Université Marien Ngouabi, Brazzaville, Congo

${ }^{2}$ Division of Research, Documentation and the Files, National Institute of Youth and Sports, Brazzaville, Congo

${ }^{3}$ Laboratory for Health and Rehabilitation, National Teaching University, Kinshasa, Congo

Email: ${ }^{*}$ jgamoulongo@gmail.com

How to cite this paper: André, M. J. G., Alphonse, M., Christophe, P. L., Didier, M. J., \& Bernard, P. T. (2016). Effects of the Rainy Ambiance on Weight Change, Haemodynamic and Thermoregulatory Adaptations in Congolese Football Players. $A d$ vances in Physical Education, 6, 396-405. http://dx.doi.org/10.4236/ape.2016.64040

Received: September 20, 2016

Accepted: November 3, 2016

Published: November 7, 2016

Copyright $\odot 2016$ by authors and Scientific Research Publishing Inc. This work is licensed under the Creative Commons Attribution International License (CC BY 4.0).

http://creativecommons.org/licenses/by/4.0/ (c) (i) Open Access

\section{Abstract}

The aim was to assess effects of the rainy ambiance on body weight, haemodynamic and thermoregulatory parameters in Congolese football players during a competition season. Thirty two football players of first division participated in this survey. The mean age was $22.0 \pm 1.7$ years. They have been divided in 2 teams: team $1(n=16)$ and team $2(n=16)$. The level of practice was comparable between topics of the 2 teams. The team 1 has been opposed to the team 2 during 6 friendly meetings in rainy and non rainy ambient. Variations of body weight, blood pressure, rectal temperature, coetaneous temperature and internal temperature have been measured before and after every meeting. The results indicate significant variations of body weight between the 2 groups: $-5.7 \%$ in rainy ambient versus $-4.79 \%$ in non rainy ambient. The higher variations were recovered at players evolving in the middle of the land, notably in the compartment $2:-6.6 \%$ in rainy ambient versus $-3.9 \%$ (non rainy ambient). Him of it was in the same way for systolic arterial pressure $(p<0.05)$, diastolic arterial pressure, pulse pressure, the higher variations $(p<0.05)$ were recovered at the level of compartment 3 (rainy ambient). The rectal temperature, as for it, underwent some meaningful variations $(p<0.05)$, the superior gaps being recorded at soccer doing meetings in rainy ambient: $\Delta \theta_{\text {rect }}=7.7 \%$ versus $3.2 \%$ (no rainy ambient). With regard to the coetaneous temperature, the variations observed between the two teams during matches were $5.5 \%$ for the team 1 and $8.9 \%$ for team 2 during rainy weather versus $5.6 \%$ and $5.7 \%$ during no rainy weather. As for the internal temperature, it varied respectively from $5.3 \%$ and $8.9 \%$ in rainy weather for the 2 teams, whereas the rates of variation amounted to $5.6 \%$ and $5.8 \%$ in no rainy 
weather. The humidity of air, the rainwater in which evolves the player, has some specific influences on the physiological adaptations at football players in equatorial environment. In conclusion, these data must challenge trainers, the technical settings of clubs and the Congolese Federation of Soccer, in the setting of the organization and the scheduling of the championship and the various tournaments.

\section{Keywords}

Rainy Ambient, Soccer, Competition, Body Weight, Haemodynamic and Thermoregulatory Adaptations

\section{Introduction}

The practice in the open air with football is under the influence of the weather conditions like showed it several studies (Thein, 1995; Bongbele et al., 1998; Vellerand, 1995). These studies were conducted in hot environment (temperature $>30^{\circ} \mathrm{C}$ ), in neutral environment $\left(20^{\circ} \mathrm{C}-25^{\circ} \mathrm{C}\right)$ or in cold environment (temperature $<10^{\circ} \mathrm{C}$ ). Significant variations were noted for body weight, heart rate (HR), blood pressure and internal temperature. Indeed, the human body adapts easily to the climatic fluctuations and expenditure thus more or less of energy to be maintained at the adequate temperature (McArdle et al., 2001). In equatorial Africa, several football meetings are played during rain. This implies that the physiological adaptations of the organization are specifically influenced by this environment. In neutral environment, a football match comprises intense phases of exercises of long duration intersected with periods of slow races fewer. This alternation suggests a reconstitution of the muscular ATP by the reaction of the phosphocreatin with a possible participation of the anaerobic glycogenolysis, aerobic way intervening during the phases of long duration (Simon et al., 1986; Palca et al., 1986). On the other hand, in hot time, the particularities are linked on the level of thermoregulation (Buskirk \& Grasley, 1987) and the cardiovascular adaptations (Newburgh, 1949) of the organism. With the cold, one notes disturbances of thermoregulatory responses, associated to sympathetic and parasympathetic nervous systems (Constance et al., 2004; Cooper, 2002).

In Congo (Brazzaville), country located in wet equatorial environment, the organization of the sporting season in football is made conspicuous by a prevalence of the rainy period at the time of the majority of the meetings. Moreover, the rain is often associated to wind; what has, of not to doubt, of the effects over the hydrous losses and the autonomous nervous system (Bongbele et al., 1998; Cooper, 2002). In the absence of data relating to the Congolese context, the aim of this study is to evaluate body weight variations, haemodynamic and thermoregulatory adaptations of the Congolese football players carrying out meetings in rainy weather. The specific objectives are to determine the variations of body weight, heart rate (HR), systolic blood pressure (SBP), diastolic blood pressure $(\mathrm{DBP})$, pulse pressure $\left(\mathrm{PP}^{0}\right)$, rectal temperature, coetaneous temperature and internal temperature. 


\section{Material and Methods}

The study, experimental, was carried out in Brazzaville from October 2015 at July 2016. This period comprised at two climatic seasons: October-December (lower rainwater precipitations: $900 \mathrm{~mm}$ fallen water) and March-May (higher rainwater precipitations: $1500 \mathrm{~mm}$ fallen water) (Clairac, 2000).

\subsection{Subjects}

On the whole, 32 football players evolving/moving in the same team of the first national division took part in this study. The criteria of inclusion were: regularity of training, agreement of the technical experts for the participation in the experimentation, morbid absence since 3 months. Their mean age was $22.0 \pm 1.7$ years (range: 18 - 26 years). The 32 subjects were divided into two teams: team 1 ( $\mathrm{n}=16$ football players); team 2 ( $\mathrm{n}=$ 16 football players) according to the level of performance. However, only the ten players of field were evaluated in each team. Their ages were comparable. These players have with the precondition undergone a medical examination near a sporting doctor of the Medical center of Brazzaville. This examination included cardiovascular, respiratory, bone health clinical examinations. The anthropometric data of the whole of players are indicated in Table 1.

\subsection{Topics}

Experimental procedure team 1 was opposed to team 2 in rainy weather initially, then in no rainy carry. During the period of study, the climatic conditions in situ were recorded at each meeting. In rainy weather, climate data were: average temperature, $28.5^{\circ} \mathrm{C}$; average relative moisture, $75.7 \%$; mean velocity of the wind, $2.2 \mathrm{~m} / \mathrm{s}$. In no rainy weather, these values were respectively of $26.3^{\circ} \mathrm{C}, 67.5 \%$ and $1.2 \mathrm{~m} / \mathrm{s}$. The rainy weather was defined by the observation of water precipitations higher than $10 \mathrm{~mm}$, whereas the no rainy weather related to a null level of precipitations (Clairac, 2000). The apparatuses used were pluviometer (model WTW OXY 330, Secchi, Switzerland) to determine the quantity of fallen rainwater (in $\mathrm{mm}$ ), hygrometer (Raytek, Cologne, Germany), anemometer (Gymrol, Saint-Etienne, France), clinical thermometer for the rectal temperature measurement (Simonsen, standard CR.W2Á, Copenhagen, Denmark). For the coetaneous temperature measurements, they were carried out on the arm, the trunk, the leg and the head using laser thermometers Minitemp (Cosma, Paris,

Table 1. Anthropometric data of football players.

\begin{tabular}{cccc}
\hline & Raining group $(\mathrm{n}=10)$ & No raining group $(\mathrm{n}=10)$ & Whole group $(\mathrm{n}=20)$ \\
\hline Age (years) & $22.4 \pm 1.7$ & $23.2 \pm 2.5$ & $22.8 \pm 2.1$ \\
Height $(\mathrm{cm})$ & $171.2 \pm 0.9$ & $170.6 \pm 1.9$ & $170.9 \pm 1.0$ \\
Weight $(\mathrm{kg})$ & $65.1 \pm 1.1$ & $66.1 \pm 2.7$ & $65.6 \pm 1.9$ \\
BMI $\left(\mathrm{kg} / \mathrm{m}^{2}\right)$ & $22.3 \pm 0.3$ & $22.9 \pm 0.5$ & $22.6 \pm 0.4$ \\
\hline
\end{tabular}

BMI, body mass index. 
France). The internal temperature was estimated by the formula of Kuznetz (1979):

$$
\theta_{\text {cent }}=\left(0.33 \times \theta_{\text {cut }}\right)+\left(0.67 \times \theta_{\text {rect }}\right) .
$$

The coetaneous temperature was also given by the means of the formulas of Kuznetz (1979):

$$
\theta_{\text {cut }}=\left(0.10 \times \theta_{\text {arm }}\right)+\left(0.60 \times \theta_{\text {trunk }}\right)+\left(0.20 \times \theta_{\text {leg }}\right)+\left(0.10 \times \theta_{\text {head }}\right) .
$$

Six matches were programmed between the two groups. These were carried out during the period of study: 3 in rainy weather and 3 in no rainy weather. All the players were subjected to the same program of training, composed of the following sequences: physical preparation, refinement of technico-tactic skills, organization of a small competition, return to a rest state, debriefing. The duration of each meeting was 3 hours. The system of play of the meetings was the 4-2-4 (Table 2).

The training proceeded between 15:00 $\mathrm{pm}-18: 00 \mathrm{pm}$. The meetings proceeded in the same site (Complex Omnisport Massamba Débat).

\subsection{Variables}

They were summarized with the determination, before and after each meet: variations of body weight ( $\Delta \mathrm{W}$ in $\mathrm{kg}$ ), $\mathrm{HR}$ (in b/min), SBP (in $\mathrm{mmHg}$ ), $\mathrm{DBP}$ (in $\mathrm{mmHg}$ ), $\mathrm{PP}^{0}$ (in $\mathrm{mmHg})$, rectal temperature $\left(\theta_{\text {rect, }}\right.$ in $\left.{ }^{\circ} \mathrm{C}\right)$, coetaneous temperature $\left(\theta_{\text {cut }}\right.$, in $\left.{ }^{\circ} \mathrm{C}\right)$ and internal temperature $\left(\theta_{\text {cent }}\right.$, in $\left.{ }^{\circ} \mathrm{C}\right)$. Those were evaluated in the ten players of field for each team. At the end of these meetings, all the variations inter seasonal of the various parameters of interest were examined in all the players of field.

\subsection{Statistical Analysis}

Data were expressed as mean \pm standard deviation (SD) or percent. Student $t$ test for weak samples $(\mathrm{n}<30)$ was used for compared two categorical and continuous variables normaly distributed. As for the comparison of values according to the compartment of occupied play, non-parametric test (Mann Whithney) was used. Traditional formula of the descriptive statistics was used for comparing variations between the two groups, for the same compartment (Sokal \& Rohlf, 1995). p-value $\leq 0.05$ defined statistical significance. All statistical analyses were performed with Mathcad, version 6.5.1 at the Division of Statistics, Department of Mathematics, Faculty of Sciences and Technology, Marien NGOUABI University of Brazzaville (Congo).

\section{Results}

Significant difference was observed between the subjects of two groups on body weight values before and after the matches. In addition, significant losses noted in the players

Table 2. Partitioning of the system of the play.

\begin{tabular}{ccccc}
\hline Compartment 1 & 11 Attacker left & 9 Central attacker & 10 Offensive medium & 7 Attacker right \\
\hline Compartment 2 & 6 Defensive medium (1) & 8 Defensive medium (2) \\
Compartment 3 & 3 Side left & 4 Hitchkiker & 5 Libero & 2 Side right \\
\hline
\end{tabular}


evolving/moving in rainy weather (Table 3), particularly on second compartment $(-5.2 \%)$. In addition, the data of Table 3 indicated significant variations of SBP before and after the meetings: $+20.8 \%$ in rainy ambient versus $+14.9 \%$ in no rainy ambient.

Variations were higher during rainy weather: $6.6 \%$ versus $-3.9 \%$ (no rainy weather). With regard to HR (Table 4), significant variations were observed before and after the meetings, particularly in favor of the players evolving/moving in rainy weather: $61.3 \pm$ $1.2 \mathrm{~b} / \mathrm{min}$ versus $65.6 \pm 0.4 \mathrm{~b} / \mathrm{min}$ and according to the compartment of football players. Values of HR were higher in rainy weather before and after the matches (Table 4), all the compartments comprising.

As for $\mathrm{PP}^{0}$ (Table 4 ), the values noted in no rainy weather were higher, the variations being significant before and afterwards in compartment 3 .

Concerning internal temperature, significant differences were perceived before and after the matches. Variations recorded during the meetings were significantly $(p<0.05)$ lower in the players carrying out of the meetings in rainy weather: $+3.5 \%$ versus $+6.2 \%$ in no raining ambient (Table 5).

\section{Discussion}

The aim of this study was to evaluate the variations of the body weight, HR, SBP, DBP, $\mathrm{PP}^{0}$, rectal temperature, coetaneous temperature and internal temperature due to the football practising and physiological stress of the rain in the high level Congolese football players. The key findings of the present study are as follows. Losses of body weight

Table 3. Variations of body weight (in $\mathrm{kg}$ ) among football players before and after competition according to compartment.

\begin{tabular}{ccccccc}
\hline & \multicolumn{3}{c}{ Raining ambient } & \multicolumn{3}{c}{ No raining ambient } \\
\cline { 2 - 7 } & Before & After & $\Delta(\%)$ & Before & After & $\Delta(\%)$ \\
\hline CP1 & $66.8 \pm 0.3$ & $64.1 \pm 0.5$ & -4.0 & $66.5 \pm 0.4^{*}$ & $63.1 \pm 0.2$ & -5.1 \\
CP2 & $65.4 \pm 1.2^{*}$ & $62.0 \pm 0.3$ & -5.2 & $65.7 \pm 0.8$ & $63.9 \pm 0.5$ & -2.7 \\
CP3 & $63.0 \pm 0.4$ & $60.6 \pm 0.3$ & -3.8 & $63.1 \pm 0.3$ & $60.9 \pm 0.4$ & -3.5 \\
Mean value & $65.1 \pm 0.6$ & $62.2 \pm 0.4$ & -4.3 & $65.1 \pm 0.5$ & $62.6 \pm 0.4$ & -3.8 \\
\hline
\end{tabular}

$\mathrm{CP}$, compartment; $\Delta$, difference between values noted before and after competition; ${ }^{\star}$, significant difference at $p<$ 0.05 .

Table 4. Variations of haemodynamic values among football players before and after competition.

\begin{tabular}{ccccccc}
\hline & \multicolumn{3}{c}{ Raining ambient } & \multicolumn{3}{c}{ No raining ambient } \\
\cline { 2 - 6 } & Before & After & $\Delta(\%)$ & Before & After & $\Delta(\%)$ \\
\hline HR (b/min) & $61.3 \pm 1.2$ & $65.6 \pm 0.4^{*}$ & +7.1 & $60.2 \pm 0.6$ & $63.8 \pm 0.3$ & +5.9 \\
SBP (mmHg) & $110.1 \pm 0.1$ & $133.0 \pm 0.4^{* * *}$ & +20.8 & $112.2 \pm 0.3$ & $128.9 \pm 0.6^{* * *}$ & +14.9 \\
DBP (mmHg) & $81.5 \pm 1.3$ & $84.7 \pm 0.5$ & +3.9 & $84.1 \pm 0.4$ & $60.9 \pm 0.4$ & +5.7 \\
PP $^{0}(\mathrm{mmHg})$ & $28.6 \pm 0.2$ & $48.3 \pm 0.4^{* * *}$ & +12.3 & $28.1 \pm 0.3$ & $62.6 \pm 0.4$ & +42.3 \\
\hline
\end{tabular}

$\mathrm{HR}$, heart rate; SBP, systolic blood pressure; $\mathrm{DBP}$, diastolic blood pressure; $\mathrm{PP}^{0}$, pulse pressure; $\Delta$, difference between values noted before and after competition; ${ }^{*}$, significant difference at $p<0.05$; ${ }^{* * *}$, significant difference at $p<0.001$. 
Table 5. Variations of rectal, coetaneous and internal temperatures among football players before and after competition.

\begin{tabular}{ccccccc}
\hline & \multicolumn{3}{c}{ Raining ambient } & \multicolumn{3}{c}{ No raining ambient } \\
\cline { 2 - 7 } & Before & After & $\Delta(\%)$ & Before & After & $\Delta(\%)$ \\
\hline$\theta_{\text {rect }}\left({ }^{\circ} \mathrm{C}\right)$ & $36.7 \pm 0.4$ & $39.1 \pm 0.3^{*}$ & +6.5 & $36.5 \pm 0.5$ & $38.6 \pm 0.2^{*}$ & +5.7 \\
$\theta_{\text {cut }}\left({ }^{\circ} \mathrm{C}\right)$ & $36.5 \pm 0.5$ & $39.0 \pm 0.6^{*}$ & +6.8 & $36.7 \pm 0.2$ & $38.8 \pm 0.4^{*}$ & +5.7 \\
$\theta_{\text {intern }}\left({ }^{\circ} \mathrm{C}\right)$ & $36.7 \pm 0.4$ & $39.1 \pm 0.3^{*}$ & +3.5 & $37.0 \pm 0.3$ & $39.3 \pm 0.2^{*}$ & +6.2 \\
\hline
\end{tabular}

$\theta_{\text {rect, }}$ rectal temperature; $\theta_{\text {cut, }}$ coetaneous temperature; $\theta_{\text {ntern, }}$ internal temperature; $\Delta$, difference between values noted before and after competition; ${ }^{*}$, significant difference at $p<0.05$.

were significant higher in the footballers carrying out of the meetings of football in rainy weather. Higher variations characterized profile of HR, SBP and various temperatures (rectal, coetaneous and internal) in the players carrying out of the meetings of football in rainy weather. However, several limitations are found in this work. First of all, it should be stressed that the $\Delta y$ variations recorded before and after, in rainy environment, translate the amplitude of variation of each variable studied under the effect of a double stress (physical and thermal). Thus, they make it possible to quantify it in real measuring unit. Moreover, the parameter speed of variation [yo] measurement the speed of variation induced by a stress in the interval of the activity. We chose the first tendency deliberately in order to describe the evolution of the studied variables, for purposes to clarify the variable of the aforesaid variations at rainy ambient temperature. The second limitation is associated to agreement with the concept of existence of a physiological steady state during the exercise. Concept of steady state or physiological balance to the exercise of maximum intensity indeed induced the positivation of the phenomenon of tiredness. Another limitation is linked to the restriction of sample at football players of Brazzaville's Department. However, Republic of Congo is divided in 9 departments characterized by variations of climate. So, one wonders to what the conclusions of the present experimental study couldn't by extrapolated to the general football players population of Congo. However, the force of this work resides on the absence of similar studies in equatorial zone (Africa, America and Asia).

It comes out from this work that the body weight losses were more significant in the players of the medium of the ground: $-6.6 \%$ in rainy weather and $-3.9 \%$ in no rainy weather. The role of distributor of the balloon falls to these players. Moreover, to distribute the balloon effectively, it should initially be received and that implies much to run to intercept it or tear off it with the adversary. It follows without any doubt a great expenditure of energy. It was brought back on this subject that the hydrous deficits are pronounced at these stations where the energy expenditure is high (Savalli et al., 2006; Debrinay, 1981). In addition, according to the system of play, the side ones (compartment 1) can from time to time go up until in attack (compartment 3). The great loss of weight obtained in compartment 1 can be allotted then partly too many long displacements of the side backs, those being sometimes transformed into wingers in order to create an excess in attack. On the other hand, the hitchkiker and the libero (compart- 
ment 1) traversed the shortest distances, seldom carrying out the rises; they are the last ramparts before the goalkeeper. Being the attackers (compartment 3), when they are effectively been useful by compartment 2 , they often traversed that small distances. However many accelerations, the vertical jumps and the many shootings can explain the loss of weight obtained with compartment 3.

Concerning the heart rate of players evolving/moving in rainy and no rainy environment, it arises that this one is comparable with that of the Congolese sedentaries of Nkoua et al. (2000): $69.0 \mathrm{~b} / \mathrm{min}$ (our series) against $70.2 \mathrm{~b} / \mathrm{min}$, for a comparable age. Our values are superposable with those noted by Kingué et al. (2001) in the Cameroonians judoists: $71.75 \mathrm{~b} / \mathrm{min}$ (by echocardiographic method). However, the drive of football requires physical exercises likely to involve a particular adaptation of the haemodynamic system. To this end, several authors report a lower HR as well in the high level footballers as at the majority of the sportsmen, compared to the witnesses (Gurtner et al., 1975; Rowell \& O'Leary, 1990; Saltin, 1985). This lowering is a function not only of one nervous sympathetic hypotonia. Also, dimensions of the higher intervenous cardiac cavities among the sportsmen of elite, at which coexist parietal hypertrophy, increase in the left ventricular mass and left ventricular dilatation (Green et al., 1996; Lash, 1998). As for SBP, our values join those of Kingué et al. (2001): $121.5 \mathrm{mmHg} \pm$ 12.9 (our series) versus $120.0 \mathrm{mmHg} \pm 12.1$. Concerning $\mathrm{HR}$, it increased on average, during meetings, of $+61.4 \%(p<0.05)$ in the players carrying out of the meetings of football in rainy weather against $+40.9 \%$ in the players carrying out of the meetings of football in no rainy weather. However in the light of these observations, it arises that the cold water of rain exerts a specific influence on the cardiovascular adaptations during sporting meetings being held in rainy environment. Thus, from a rheological point of view, it pay that during a meeting proceeding in times of rain, the incidence of the environment of the environment clearly does not accelerate the phenomena of fast adaptation of the cardiac function à the exercise. Speed with which these adjustments are carried out of is thus limited. On the other hand, this adaptation involves a level of definitely lower HR in thermal condition neutral, but higher than that recorded in cold thermal condition: $137.6 \mathrm{~b} / \mathrm{min}$ with $20^{\circ} \mathrm{C}$ after $95 \mathrm{~min}$ of exercise (Fach et al., 1989) against $107.08 \mathrm{~b} / \mathrm{min}$ in our players.

Moreover, the exposure of all the organization to the rain produces systemic answers which all are indicative of an activity of the nervous sympathetic system (Convertino, 1991; Hayward, 1977). In addition, the stimulation of the nervous sympathetic system appears in times of rain by an increase in SBP and DBP (Convertino, 1991), by a rise of HR (Convertino, 1991), like by a change of the cardiac flow (Green et al., 1996). These reactions are typical cooling of the distal parts. However, the exposure of the figure to rainwater, in equatorial climate, also brings a tachycardia related to a lifting of vagal inhibition; what explains the no significant rise in the blood pressure by reduction of the peripheral blood flood to the profit of an adequate central circulation. Moreover, rises in SBP and DBP in the players evolving/moving in rainy weather can be also explained by the relations of Fagard (Fagard, 1985), connecting the blood pressure noted to the 
beginning of the match with the intensity of work. As for the rectal temperature, it increased on average, during meetings, of $+7.7 \%$ in the players carrying out of the meetings of football in rainy weather against $+3.2 \%$ in no rainy weather, the difference being significant $(p<0.05)$. The weak variations observed are undoubtedly ascribable by character little differentiated from the dissipative function of energy $\left[\mathrm{Q}^{-1}\right]$ for the whole of the cardiorespiratory system. These factors thus contributed in a way significant to cause a considerable hydrous loss by sudation, contrary to the subjects evolving/moving in rainy weather.

Lastly, with regard to the temperatures coetaneous and central, they differ significantly in rainy and no rainy weather. Moreover, Cissé et al. (1997) concern in young Senegalese sportsmen comparable age, a change of the coetaneous temperature (thorax) and intern, in no rainy weather and heat: $\theta_{\text {cut }}=35.31^{\circ} \mathrm{C} \pm 0.52^{\circ} \mathrm{C}$ and $\theta_{\text {rect }}=37.29^{\circ} \mathrm{C} \pm$ $0.40^{\circ} \mathrm{C}$. Our observations confirm a well-known concept: the coetaneous temperature varies with the ambient temperature (Benzinger, 1969; Casa, 1999). The thermal rise caused by rainwater is in relation to the more increased activation of the nervous sympathetic system. Indeed, catecholamines stimulate the use of the muscular system and the production of lactates. The values of the internal temperature are less low at our subjects in rainy weather. Thus, the internal temperature is in relation to the ambient temperature. However, one should not neglect in rainy weather the role of thermogenesis induced by the acclimatization (Prentice, 2003; King et al., 1985). Moreover, one precise determination of the internal temperature is related on the coetaneous temperature and the rectal temperature as Kuznetz (1979) bring it back. Indeed, the first which translates the mechanisms of thermoregulation better carries out by the use of a relation taking of account the temperatures of the face, the chest, the leg and the thigh, in accordance with the methodology of Savalli et al. (2006). All things considered, the variations in the coetaneous temperature, rectal temperature and central temperature during meetings in rainy weather are of not to be doubted due to the increase in the rate of adrenalin in blood.

\section{Conclusion}

The present study has showed that rainy environment modified body weight, haemodynamic adaptations and thermoregulatory profile in the football players in Congolese equatorial climate. These variations were more significant in the players evolving/moving in rainy weather, in particular at those of the medium of the ground. Thus, it is advisable to acclimate the footballers in rainy ambient for minimizing the stress of training in such environment.

\section{References}

Benzinger, T. H. (1969). Heat Regulation: Homeostasis of Central Temperature in Man. Physiological Reviews, 49, 671-759.

Bongbele, J. et al. (1998). Influence du poste sur la perte du poids corporel des footballeurs en ambiance chaude. Médecine du Sport, 7, 130-134. 
Buskirk, E. R., \& Grasley, W. C. (1987). Heart Injury and Conduct of Athletes. Science and Medicine of Exercise and Sports. 3st Edition, Harper and Sons, New York.

Casa, D. J. (1999). Exercise in the Heat. I. Fundamentals of Thermal Physiology, Performance Implications, and Dehydratation. Journal of Athletic Training, 34, 246.

Cissé, F. et al. (1997). Evolution of the Rectal Temperature at 24 Hours in Tropical Climate Witch and Nutritional Contribution. Dakar Medical, 4, 19-24.

Clairac, B. (2000). Climate of the Area of the Pool-Brazzaville. In: Senechal, A., Kabala, M. and Baker, R., Eds., Review of Knowledge on the Climate of Congo-Brazzaville, UNESCO-UNDP, Paris, 45-68.

Constance, R. et al. (2004). Recovery of Articular Cartilage Metabolism Following Thermal Stress Is Facilitated by IGF-1 and JNK Inhibitor. The American Journal of Sports Medicine, 32, 191-196. http://dx.doi.org/10.1177/0363546503260743

Convertino, V. A. (1991). Blood Volume: Its Adaptation to Endurance Training. Medicine Science Sports Exercise, 23, 1338-1348. http://dx.doi.org/10.1249/00005768-199112000-00004

Cooper, K. E. (2002). Molecular Biology of Thermoregulation: Some Historical Perspectives on Thermoregulation. Journal of Applied Physiology, 92, 1717-1724. http://dx.doi.org/10.1152/japplphysiol.01051.2001

Debrinay, A. (1981). Hydrous Losses and Liquid Contribution in Football. The French Trainer, 178, 1-3.

Fach, H. H. et al. (1989). Effects of Different Temperatures on Stress and Performance Activity in Sport. Journal of Sport Science, 7, 41-63.

Fagard R. (1985). Training and Blood Pressure in Sportsmen. International Journal of Medicine, 6, 57-65.

Green, D. J. et al. (1996). Control of Skeletal Muscle Blood Flow during Dynamic Exercise. Sports Medicine, 21, 119-146. http://dx.doi.org/10.2165/00007256-199621020-00004

Gurtner, H. P. et al. (1975). Normal Values for Pulmonary Hemodinamics at Rest and during Exercise in Man. Progress in Respiratory Research, 9, 295-315. http://dx.doi.org/10.1159/000398202

Hayward, J. N. (1977). Functional and Morphological Aspects of Hypothalamic Neurons. Physiological Reviews, 57, 577-658.

King, D. S. et al. (1985). Muscle Metabolism during Exercise in the Heat in Unacclimatized and Acclimatized Humans. Journal of Applied Physiology, 59, 1350-1354.

Kingué, A. et al. (2001). Cardiovascular Characteristics of the Cameroonians Judoists. Science \& Sports, 38, 107-113.

Kuznetz, L. H. (1979). A Two-Dimensional Transient Mathematical Model of Human Thermoregulation. American Journal of Physiology, 237, R266-R277.

Lash, J. M. (1998). Training-Induced Alterations in Contractile Function and Excitation-Contraction Coupling in Vascular Smooth Muscle. Medicine \& Science in Sports \& Exercise, 30, 60-66. http://dx.doi.org/10.1097/00005768-199801000-00009

McArdle, W. D. et al. (2001). Exercise Physiology. Lea \& Febiger, Philadelphia.

Newburgh LH. (1949). Physiology of Heat Regulation. Saunders, Philadelphia.

Nkoua, J. L. et al. (2000). Cardiovascular Profile of Congolese Healthy Old from 20 to 45 Years. Black Medicine of Africa, 4c, 21-26.

Palca, J. W., Walker, J. M., \& Berger, R. J. (1986). Thermoregulation, Metabolism, and Stages of Sleep in Cold-Exposed Men. Journal of Applied Physiology, 61, 940-947. 
Prentice, W. E. (2003). Principles of Athletic Training (11th ed.). New York: McGraw-Hill.

Rowell, L. B., \& O'Leary, D. S. (1990). Reflex Control of the Circulation during Exercise: Chemoreflexes and Mechanoreflexes. Journal of Applied Physiology, 69, 407-418.

Saltin, B. (1985). Hemodynamic Adaptations to Exercise. The American Journal of Cardiology, 55, D42-D47. http://dx.doi.org/10.1016/0002-9149(85)91054-9

Savalli, L., Olave, P., Hernandez Sendin, M. I., Laboute, E., Trouvé, P., \& Puig, P. L. (2006). Whole-Body Cryotherapy $-110^{\circ} \mathrm{C}$. Measure of Skin and Central Temperature to the Sportsman. Science \& Sports, 21, 36-38. http://dx.doi.org/10.1016/j.scispo.2006.01.005

Simon, E., Pierau, F. K., \& Taylor, D. C. (1986). Central and Peripheral Thermal Control of Effectors in Homeothermic Temperature Regulation. Physiological Reviews, 66, 235-300.

Sokal, R. F., \& Rohlf, S. W. (1995). Biometry (5th ed.). San Francisco, CA: Freeman and Co.

Thein, L. (1995). Environmental Conditions Affecting the Athlete. Journal of Orthopaedic \& Sports Physical Therapy, 21, 158-171. http://dx.doi.org/10.2519/jospt.1995.21.3.158

Vellerand, A. (1995). Exercise in the Cold. In J. Torg, \& R. Shephard (Eds.), Current Therapy in Sports Medicine. Saint Louis: Mosby.

\section{Submit or recommend next manuscript to SCIRP and we will provide best service for you:}

Accepting pre-submission inquiries through Email, Facebook, LinkedIn, Twitter, etc.

A wide selection of journals (inclusive of 9 subjects, more than 200 journals)

Providing 24-hour high-quality service

User-friendly online submission system

Fair and swift peer-review system

Efficient typesetting and proofreading procedure

Display of the result of downloads and visits, as well as the number of cited articles

Maximum dissemination of your research work

Submit your manuscript at: http://papersubmission.scirp.org/

Or contact ape@scirp.org 